\title{
Explosive pulsed plasma antennas for information protection
}

\author{
Igor V. Minin and Oleg V. Minin \\ Novosibirsk State Technical University \\ Russia
}

\section{Introduction}

Since the discovery of radio frequency ("RF") transmission, antenna design has been an integral part of virtually every communication and radar application. In its most common form, an antenna represents a conducting metal surface that is sized to emit radiation at one or more selected frequencies. Antennas must be efficient so the maximum amount of signal strength is expended in the propogated wave and not wasted in antenna reflection. The modern requirements to antenna include compactness and conformality, rapid reconfigurability for directionality and frequency agility and should also allow low absolute or out-of-band radar cross-section and facilitate low probability of intercept communications. The need for an antenna that is "invisible" (thus not detectable while not in operation) has, already in the 1980's, sparked work on the feasibility of using an atmospheric discharge plasma ${ }^{1}$ as an RF antenna. Moreover, data communications can be made more secure if the antenna only "exists" during the transmission of each data packet. Such antennas use plasma formations as the receiver or transmitter elements. The characteristics of the plasma formations are determined by purpose of the specific antenna. Plasmas have two important properties that are relevant for interaction with electromagnetic waves:

- For frequencies above the plasma frequency, a semi-infinite plasma transmits EM waves with a wavelength, 1 / $\mathrm{e}_{\mathrm{r}}$ where 1 is the free space wavelength. Thus plasmas can in principle be used for electronic tuning or control of a radiation pattern by varying the plasma density. For the densities typical of discharge tubes, this phenomenon appears especially useful at microwave frequencies.

- For frequencies below the plasma frequency, however, the dielectric constant is $\mathrm{e}_{\mathrm{r}}<$ 0 , the plasma behaves as a metal, free space EM waves cannot penetrate, and are reflected. Radio communications via the ionosphere rely on this effect.

Plasma technology can be utilized to create secure WiFi data transmission capability for use in different applications up to $100 \mathrm{GHz}$ [33]. WiFi has enabled a wide array of inexpensive communication devices that are utilized in desk-top computing, networking, PDA's etc. Its

${ }^{1}$ Sir William Crookes, an English physicist identified a fourth state of matter, now called plasma, in 1879 . 
biggest drawback is data transmission security. When plasma is not energized, it is difficult to detect by radar. Even when it is energized, it is transparent to the transmissions above the plasma frequency, which falls in the microwave region. This is a fundamental change from traditional antenna design that generally employs solid metal as the conducting element. Additionally, a transient antenna does not interfere with any other antenna based communication system. The term transient antenna, used here, refers to an antenna that changes radiation characteristics over time. This may be accomplished by varying the dimensions, impedance, or conductivity of the antenna or by changing its position with respect to other radiating elements. Transient antenna technology is relatively new. Such a thin plasma channel can be produced using high explosives.

It has long been known that plasma, ionized gas, can be used as an antenna, however, further investigations have not come until recently, because it was believed to be impossible to produce long plasma objects with high electron densities $\left(>10^{20} \mathrm{~cm}^{-3}\right)$ [1]. Several experiments and investigations have shown that high electron density levels are achievable. Numerous investigations around the world have been conducted in order to characterize the operation of this class of antennas.

Plasma antennas offer several advantages for different applications, having:

1. compactness and conformability;

2. rapid configurability for directionality and frequency agility;

3. low allowance of absolute or out-of-band radar cross section;

4. low probability of communications interceptions;

5. higher digital performance in commercial applications;

6. very large frequency capabilities, ranging from a fraction of a Hertz to several Giga Hertz or more;

7. practically zero mass;

8. capacity for instant creation and rapid disappearance [1].

Also a problem with metal antennas is their tendency to "ring". That is once you turn off the drive frequency, they continue to radiate as the oscillations die down. This can pose a serious problem for the short range ground penetrating radars used in petrochemical and mineral exploration. However because of their rapid switchability, plasma antennas don't ring. So a fundamental distinguishing feature is that after sending a pulse the plasma antenna can be deionized (or time of life of plasma antenna is about a pulse), eliminating the ringing associated with traditional metal elements. Ringing and the associated noise of a metal antenna can severely limit capabilities in high frequency short pulse transmissions. In these applications, metal antennas are often accompanied by sophisticated computer signal processing. By reducing ringing and noise, we believe plasma antenna provides increased accuracy and reduces computer signal processing requirements. These advantages are important in cutting edge applications for impulse radar and high-speed digital communications.

The design allows for extremely short pulses, important to many forms of digital communication and radars. The design further provides the opportunity to construct an antenna that can be compact and dynamically reconfigured for frequency, direction, bandwidth, gain and beamwidth. Plasma antenna technology will enable antennas to 
be designed that are efficient, low in weight and smaller in size than traditional solid wire antennas.

Today there are well known the following main types of plasma antennas:

- Laser Induced antenna. As it was known by the authors the laser induced antenna was offered by Askar'yan G. A. [2]. Possibilities of the plasma application for antenna parameters control have been proposed in the sixties of 20 century. The transmission was realized along a plasma channel that was created by the atmosphere breakdown. The atmosphere breakdown was created by the focused laser emission. Later, for example, Dwyer et al. [3] discussed the use of a laser to assist in the ionization of paths up to several meters. The laser is used to designate the path of the antenna while an electrical discharge is employed to create and sustain the plasma. As a rule plasma antenna produced by the discharge of a Marx generator.

- Plasma Antennas Using Tube Structures. At Australian National University, a sealed-glass tube design, fed by a capacitive coupler was employed [4]. When the plasma creating voltage is turned off, the antenna effectively disappears. An efficiency of $50 \%$ was observed, the radiation patterns were predictable, and lowbase-band noise for HF and VHF transmissions was recorded. The glass tube design can be very effective in providing the desires previously mentioned. When the glass tube is not energized, no plasma exists; therefore the antenna is nonconducting and incapable of coupling an EMP. If the antenna is energized with a low plasma frequency, an EMP will simply pass through the plasma without coupling into the device.

- Explosively Formed Plasma Dielectric Antennas. Another approach to creating plasma is with the use of explosives. Altgilbers et al. [5] discussed the possibilities of using an explosive driven plasma jet as an antenna. A simple explosive charge design, called a plasma cartridge (Figure 1), can be used to generate a column of ionized gas. In this design, 1-3 grams of seeded explosive charge, which contained $\mathrm{Fe}, \mathrm{Pb}, \mathrm{C}, \mathrm{N}, \mathrm{K}, \mathrm{CI}$, and $\mathrm{O}$ was used to create plasma. The jet obtained a distance of $4 \mathrm{~m}$ in $1 \mathrm{mks}$. Due to the high temperatures generated by the explosive material, the surrounding gases became ionized, forming a plasma column. Altgilbers et al. [5] stated that the plasma generated by the plasma cartridge had a temperature of 3650 $\mathrm{K}$ with an estimated plasma density of $5 \times 10^{19} \mathrm{~cm}^{-3}$. The temperatures required to produce these plasmas are a direct result of the specific explosive constituents employed. Most likely, though it is not stated, this plasma cartridge design used potassium perchlorate or some other high temperature producing oxidizer. For the fuel in the explosive to bum, oxygen is required and the amount provided in the atmosphere is minimal compared with oxidizing agents. Typical high explosives contain an oxidizer in order to provide an ample amount of oxygen for the fuel, which ensures that all of the fuel contributes to the explosive process [6]. The maximum attainable temperature that can be achieved is dependent upon the available oxygen for fuel recombination. It has been proven that a plasma jet antenna is feasible, but the details of such a design are not yet fully understood [5]. 
It is shown [5] that the pulsed current in the solenoid couples its energy through excite transiently varied electric and magnetic fields in the plasma jets, which are produced by explosives. The electric and magnetic fields accelerate/decelerate electrons and cause the plasma jets radiate the energy out. The possible radiation mechanisms, which have been discussed above include the line emission, the continuum radiation, and the plasma radiation. After studying their radiation powers and frequencies, it is seen that the line emission and continuum radiation including Bremsstrahlung and recombination are not influenced by the pulse current in the solenoid. the frequencies of these types of radiation are in a wide range up to $105 \mathrm{GHz}$. The energy of the plasma radiation such as electron cyclotron radiation, pulse oscillation radiation, sequence dipole oscillation radiation, and surface wave radiation are coupled from the pulse current in the solenoid. The frequencies of these radiations are in a rather narrow range with an order about GHz. The electron cyclotron radiation and pulse oscillation radiation are shown to be much weaker than the dipole oscillation radiation and surface wave radiation. The same investigations of a plasma dielectric antenna with other design was also made in [7]. It were shown that the main properties of such an antenna are: 1) plasma antenna action has many general with the dielectric antenna action; 2) plasma antenna is designed for pulse operation.

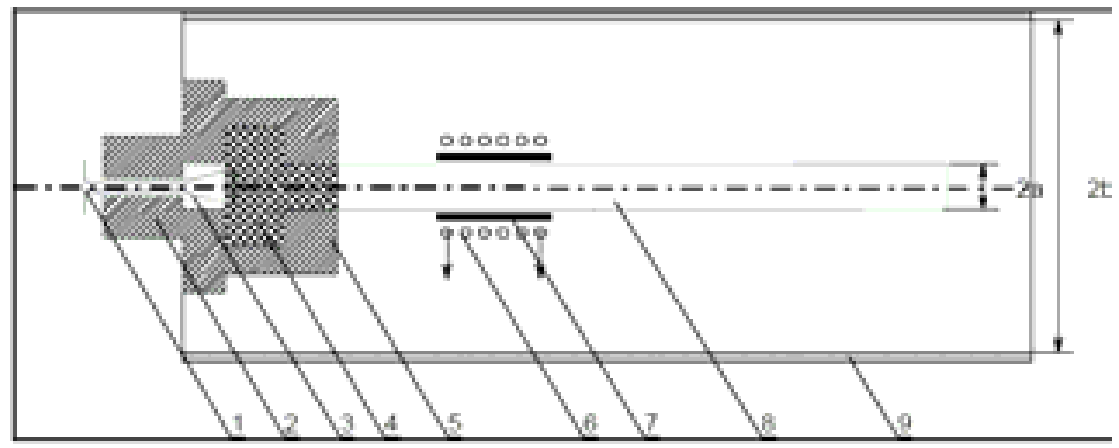

Fig. 1. Diagram of a plasma cartridge [5]. I- input wires from power source, 2- connecters, 3bridgewire, 4- explosives, 5-cartridge housing, 6- lew frequency solenoid, 7- high frequency solenoid, 8- ferrite inserts, 9- plasma jet, and 10- cyfindrical metal casing.

Experimental investigations of multi-jet plasma dielectric antennas are described at [8]. A plasma antenna with four jets has been designed, built, and tested. The design of multi-jet plasma antenna with the H-waveguide excitation system is shown at the Fig. 2.

Comparison of the simulation results for the antenna, operating at the frequency of 700 $\mathrm{MHz}$, with four and six HE-shaped jets, shown that the basic characteristics of both antennas are virtually same. Analyzing the results of computer simulation, shown at the Fig. 3 , it is possible to see that at the frequencies of $700 \mathrm{MHz}$ the influence of plasma jets is substantial enough for their length of $200 \mathrm{~mm}$.

It was demonstrated that this antenna can achieve more than 6-7 $\mathrm{dB}$ of gain at a frequency of $700 \mathrm{MHz}$. 
So according to [5] today there are well known three main physical types of plasma antennas: 1) plasma dielectric antennas, 2) plasma horn antennas and 3) plasma mirror antennas. Additional a plasma jet produced by an explosive cartridge, if properly designed, is the one of the most suitable form of this antenna. The disadvantage is the chemical composition of the explosive must be carefully chosen to ensure that the antenna operates in a nonlinear mode so as to enrich its high-frequency spectral output. But the use of explosives in order to generate transient antennas is net limited to plasma designs alone. It has been shown that the use of a high velocity metal jet resulting from a shaped charge explosive design is capable of generating such an antenna [9-11].

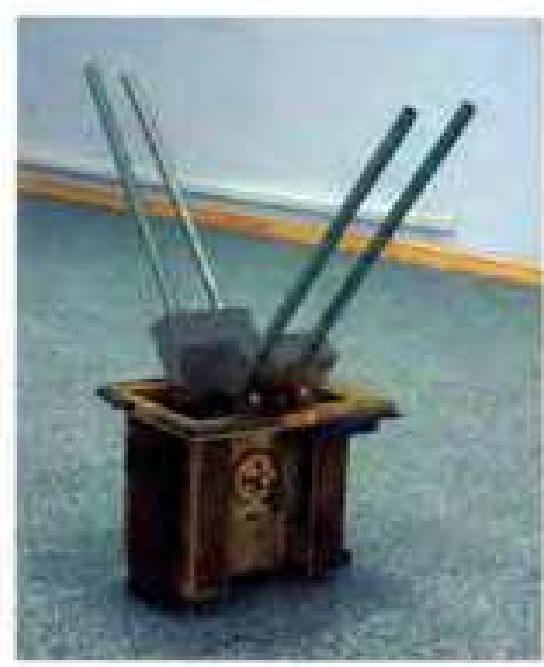

Fig. 2. Plasma dielectric antenna with four jet [8].

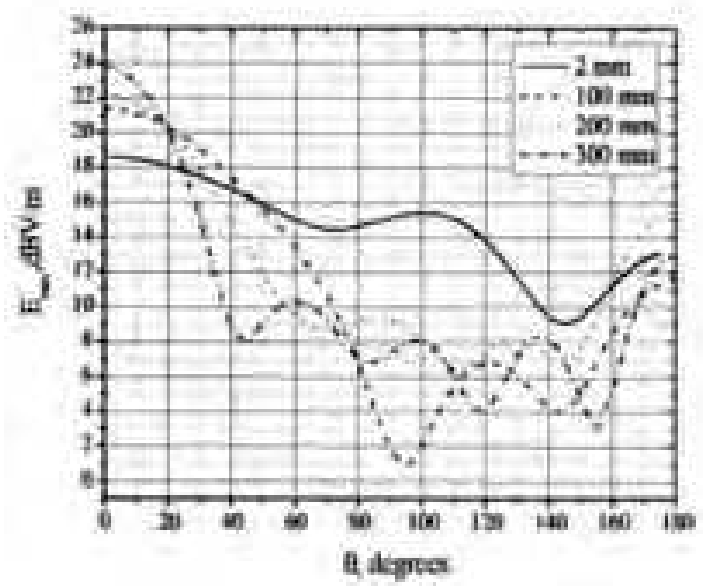

Fig. 3. E-field strength of a four-jet plasma antenna in E-plane for different length of a conductive plasma jet. Frequency is $700 \mathrm{MHz}$ [8]. 


\section{Shaped Charges as Transient Antennas}

The shaped charge antenna design, frozen in time, resembles a monopole antenna. Even though the jet produced is not a perfect cylinder, as discussed later, the model for an ideal monopole can be used to predict the results. In the same way, two shaped charges placed back to back resemble a dipole antenna. In fact, the metal jets can be arranged in several different configurations in order to produce several different antenna designs. One example of shaped charge 9 jet configurations is shown in the figure 4 [12].

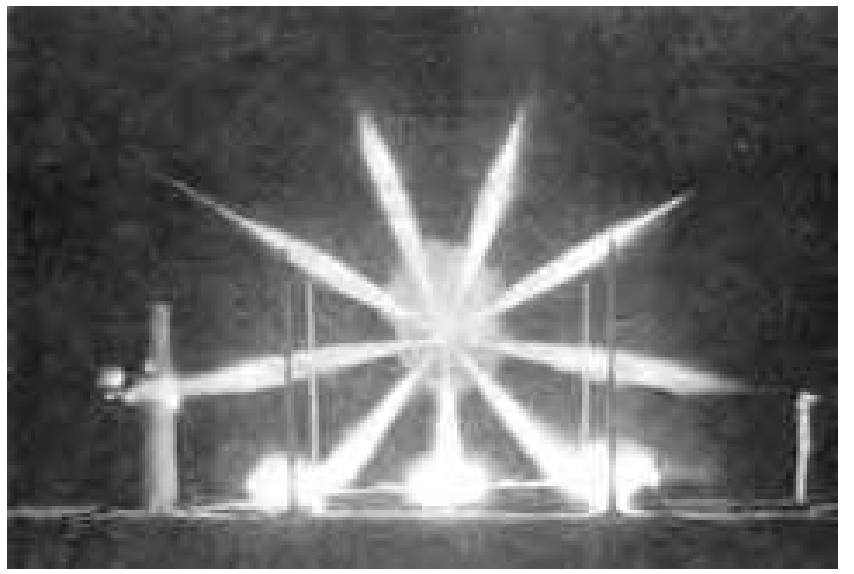

Fig. 4. The shaped charge 9 jet experimental configuration developed by D.R. Kennedy [12].

\subsection{BRIEF SHAPED CHARGE HISTORY}

A cylinder of explosive with a hollow cavity in one end and a detonator at the opposite end is known as a hollow charge. The hollow cavity, which may assume almost any axissymmetric geometric shape such as a hemisphere, cone, ellipse, tulip, trumpet, dual angle cone, pyramid, or the like, causes the gaseous products formed from the initiation of the explosive at the end of the cylinder opposite the hollow cavity to focus the energy of the detonation products. The focusing of the detonation products creates an intense localized force. This concentrated force, when directed against a metal plate, is capable of creating a deeper cavity than a cylinder of explosive without a hollow cavity, even though more explosive is available in the latter case.

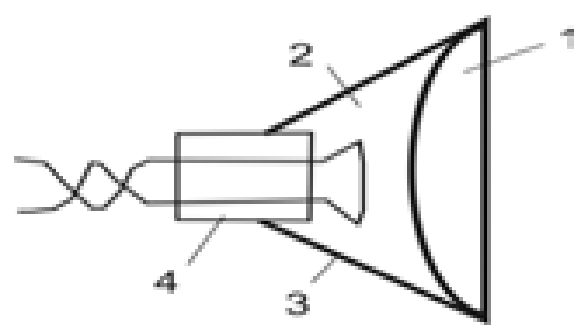

Fig. 5. Shaped charge developed by captain Andrievsky: 1- sawdust, 2 - gunpowder, 3 body, 4 - electroigniter. 
This phenomenon is known in the U. S. and Britain as the Munroe effect (1885) and in Europe as the von Foerster (1883) or Neumann (1910, but no practical applications were developed) effect [12]. This phenomenon also was discovered by Russian general Boreskov in 1864 [13]. Later Russian captain Andrievsky in 1865 developed a special charge for detonation of explosive (see figure 5).

If the hollow cavity is lined with a thin layer of metal, plastic, ceramic, or similar materials, the liner forms a jet when the explosive charge is detonated. Upon initiation, a spherical wave propagates outward from the point of initiation for the basic case of a single point initiated charge, initiated along the axis of symmetry. This high pressure wave moves at a very high velocity, typically around $8 \mathrm{~km} / \mathrm{s}$. As the detonation wave engulfs the lined cavity, the liner material is accelerated under the high detonation pressure, collapsing the liner. During this process, for a typical conical liner, the liner material is driven to very violent distortions over very short time intervals (microseconds) at strain rates of $10^{4}$ to $10^{7}$ /s. Maximum strains greater than 10 can be readily achieved since superimposed on the deformation are very large hydrostatic pressures (peak pressures of approximately $200 \mathrm{GPa}$, decaying to an average of approximately $20 \mathrm{GPa}$ ). The collapse of the liner material on the centerline forces a portion of the liner to flow in the form of a jet where the jet tip velocity can travel in excess of $10 \mathrm{~km} / \mathrm{s}$. The conical liner collapses progressively from apex to base under point initiation of the high explosive. A portion of the liner flows into a compact slug (sometimes called a carrot), which is the large massive portion at the rear of the jet. Slugs constitute 80 to $85 \%$ of the jet mass and typically travel at about $1 \mathrm{~km} / \mathrm{s}$. The pressures generated during the liner collapse far exceed the yield strength of the liner material and thus the liner behaves approximately as an in viscid, incompressible fluid [14].

Many efforts have been made over the years to understand the process of jet formation regarding the various modes of jet formation, i.e., formation of jets from conical, hemispherical, and etc. liners. Early work on shaped charges showed that a range of alternative constructions, including modifying the angle of the liner or varying its thickness, would result in a faster and longer metal jet. These research and development efforts to maximize penetration capabilities were based largely on trial and error. While the concept of a metal surface being squeezed forward may seem relatively straightforward, the physics of shaped charges is very complex and even today is not completely understood.

Now in the theory of functioning of cumulative charges there was a quite certain sight on a nature of a without the jet collapse of facing of a cumulative liner and formation of a dispersion of cumulative jets. In formation of this sight the basic role the works $[15,16,17]$ have played.

The hydrodynamical theory of a cumulative jet offered by G.Taylor and G.Birkhoff [18] and M.Lavrent' ev [19] , allows to receive the analytical decision of a task as a first approximation at the assumption, that the process of formation of a jet follows the laws of the stationary expiration.

In [17] on the basis of the analysis of various experimental data and results of numerical accounts the criterion of formation of compact cumulative jets is offered which says: the speeds impacting of jets in system of coordinates moving with phase speed, should be subsonic.

Problems concerning the stationary impacts of flat contracted jets are also resolved by employing a model that is based on the behaviors of ideal fluids [15]. The geometrical and kinematic parameters of jets can be defined when there no derivated inverse (cumulative) 
jets at their impact point. In a rotationally symmetric case the criterion of Wolsh is inapplicable, as is indicated by the possible lack of inverse (back) jet formation due to the development of dissipative processes. The embodiment of such a condition in practice is possible at small jet impact velocities. In a rotationally symmetric case the criterion for formation of compact cumulative jets is offered on the basis of the analysis of different data resources (both experimental and calculation) [17]. The fundamental criterion states: the velocities of impacting jets in a frame moving with a phase velocity should be subsonic.

In mid-50 years of the $20^{\text {th }}$ century Wolsh and his co-authors published papers dedicated to the study of steady-state symmetrical impacts of flat supersonic jets. This work was an essential addition to the hydrodynamic theory of a cumulative jet formation. It established criteria regarding the formation of a cumulative jet, with these being related to observations of the behavior a flat shaped-charge impact. Subsequently, a ranking of criteria were formulated for jet formation that incorporate all the current nomenclature related to shaped charges, including both non-stationary and rotationally symmetric cases. The expressed criticism of this approach's practical applicability in a rotationally symmetric case has not had any effect on its general "authority". Indeed, Wolsh et al.'s criteria are justified by practical examinations of the conditions needed for the formation and maintenance of compact cumulative jets, and are, as a rule, of great interest. Examining these conditions demands the observance of rigorous requirements, and even more so than was the case in Wolsh et al's pioneering work. However, the essential observable and replicable condition is that the formation of a cumulative jet requires that the impact of jets happen at subsonic speeds

The application of Wolsh's jet formation criterion [15] to a typical non-stationary case and to cases wherein currents exist with rotational symmetry is not substantiated by the relevant and precise theoretical results.

In the works [20-21] the criterion of Wolsh is distributed on a non-stationary case. It was shown, that in a rotationally symmetric case the criterion of Wolsh is inapplicable. Also it was described, that in a rotationally symmetric case that is produced by a current associated with a symmetrical axis produced by a shock wave can never be realized. That is, that cumulative jets will always be formed. This depends on the velocity function and angle of impact, wherein the formation of continuous, partially dispergated and completely dispergated jets (stream of macroscopic particles) is possible. So the quality of a jet will depend on distance of a shock wave up to an axis of symmetry. At rather small distances such jet will be intensively dispersive and to represent a flow of high-speed particles.

\subsection{Shaped charge for plasma antenna design consideration}

The goal of shaped charge design [22] was to produce a metal jet capable of radiating electromagnetic energy effectively into free space. It was determined that the frequency range for operation would be around $1 \mathrm{GHz}$, thus a jet length of $75 \mathrm{~mm}$ (quarter wavelength) was required. The jet had to be capable of carrying current the entire distance required. Therefore, the shaped charge had to be designed so that the jet did net particulate or become non-coherent before it reached $75 \mathrm{~mm}$ in length. Composition-C4 was the explosive chosen for use at shaped charge. The decision for the liner material was copper; the casing was made of aluminum. Diameter of shaped charge liner was $29.8 \mathrm{~mm}$, the mass of the jet was $3.84 \mathrm{~g}$, the mass of the slug $-18.64 \mathrm{~g}$, total mass of the liner was $22.48 \mathrm{~g}$, and 
explosive mass was $40.37 \mathrm{~g}$. It was determined that the velocity of the jet tip was approximately $3.9 \mathrm{~km} / \mathrm{s}$. The length of the jet was approximately $103 \mathrm{~mm}$ (figure 6).

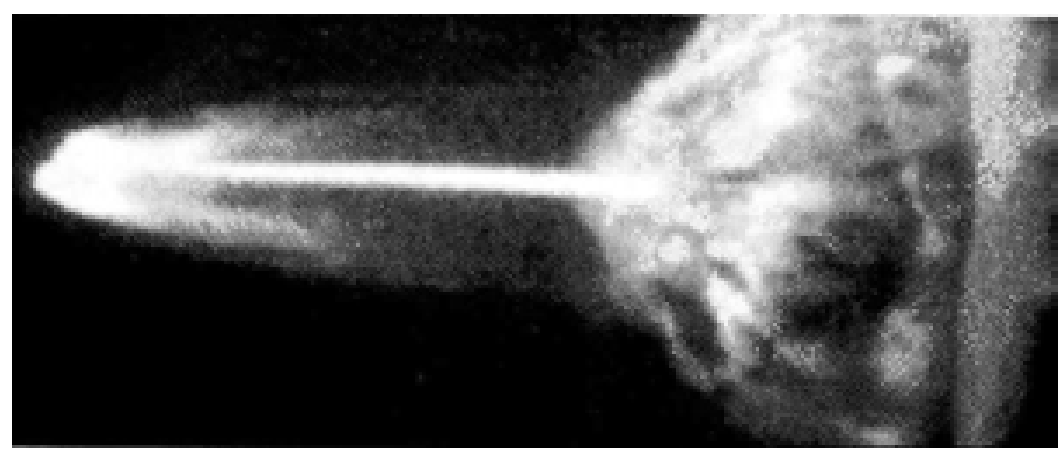

Fig. 6. Shaped charge jet $40 \mathrm{mks}$ after detonation [22].

It was concluded that the metal jet created by this shaped charge design was capable of achieving a conductive length of at least the required $1 \mathrm{GHz}$ quarter wavelength. Calculations shown that in the ideal case, the receiving antenna should collect $33 \mathrm{~mW}$ of power if $1 \mathrm{~W}$ of power is successfully radiated into free space by the shaped charge antenna. Previously, it was assumed that the resonant length of the shaped charge would be $75 \mathrm{~mm}$ based on known antenna characteristics. Given that the shaped charge jet did not represent an ideal monopole exactly, it was expected that the actual resonant length would be slightly different.

Due to the corresponding changes in reflected and received power with relation to time, it was concluded that transmission of energy from the transient antenna to the dipole was successful [22] - see figure 7. The maximum value received by the dipole in each test (approximately $4 \mathrm{~mW}$ ) was much less than the measured value of $14 \mathrm{~mW}$ for the mockup. A couple of possibilities exist that may explain these apparent losses.

The tests revealed an apparent power dissipation of up to $90 \%$ over duration of $5 \mathrm{mks}$ is for the $1 \mathrm{GHz}$ frequency regime. It is not known exactly how much of that dissipated power is divided between heat and radiation; however preliminary calculations suggest that ohmic losses are minimal and radiation efficiency is close to $100 \%$. Similar results were discovered in the $915 \mathrm{MHz}$ thin wall and thick wall tests. Each of the tests revealed comparable values for the maximum power received by the dipole antennas.

The effective use of a shaped charge as a transient antenna greatly depends en the ability of the design to limit particulates and off-axis breakup. These two factors dictate the maximum length that can be achieved by the design and the path taken by the current. The coherency of the jet determines the current path, which is a major contributing factor to the resulting polarization and the subsequent field pattern of the antenna. Given that the apex angle value affects all of the critical velocities, the particulates event, and coherency status of the jet, future research should focus primarily en the dependence of success on this parameter [22]. 

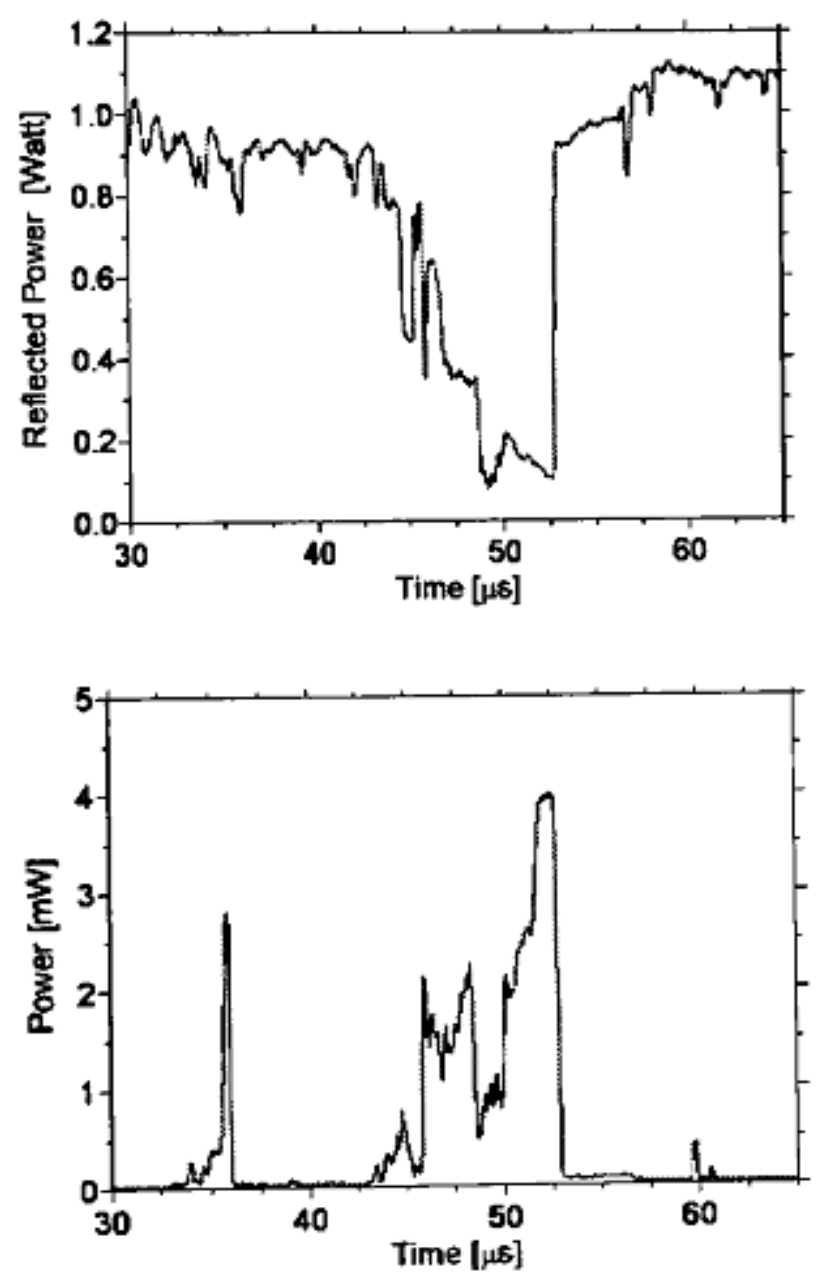

Fig. 7. Reflected (top) and received (bottom) power for $1 \mathrm{GHz}, 1.95 \mathrm{~mm}$ liner thickness test [22].

\subsection{The main disadvantages}

Over time, the jet begins to follow a phenomenon referred to as particulation. As the jet propagates, the liner material particulates into several smaller pieces along the axis of the jet. It is assumed that particulation first occurs between the neck and the head of the jet. At the interface between these two parts, a considerable velocity gradient (several $\mathrm{km} / \mathrm{s}$ differences) exists and eventually, the head pulls away from the neck. After this initial particulation, the rest of the jet begins to breakup and if uninterrupted, will particulate completely. Characterization of the time before particulation, or breakup time, is of great importance to shaped charge designers. 
The breakup time of the jet can be increased by:

1. increasing the jet radius,

2. decreasing the jet stretching rate,

3. decreasing the jet strength,

4. increasing the jet density,

5. increasing the dynamic ductility [14].

Another concern that can have a dramatic effect on the length of a shaped cha rge is jet coherency. This refers to the coherency of the jet in the radial direction, which occurs symmetrically about the jet axis. A so-called coherent jet is one that has very little deviation away from that axis. Similar to particulation, a noncoherent jet is one that results in breakup into smaller particles. The particles are off-axis, therefore, spreading the force of the jet to a larger area.

\section{Pulsed Explosive Dielectric Plasma Antenna}

During the flaying in air the metal jet of shaped charge produced plasma. The flight of hypersonic bodies in the air is accompanied by intense processes of gas and body surface heating, its erosion and ablation. At the same time, temperature near the body surface and the intensity of these processes are higher, for greater density and pressure of the environmental gas [10].

The detailed results of experimental investigations of properties of low-temperature air plasma that is initiated by hypersonic bodies moving at velocities close to the first cosmic velocity (M 17) was described at [10]. It was discovered [23] a new physical regularity in that the plasma trace parameters could be characterized by the grain size of the surface microstructure of the hypersonic body (at a fixed velocity, shape and surface material of the hypersonic body). The experiments show the following properties of non-ideal air plasma (non-ideal parameter $\gamma=0.15$ ) with a condensed dispersed phase. To intensify the processes and for studying the character features of the flight in extreme conditions, the model experiments were conducted in air in the normal initial state. The technique of X-ray and mm-wave diagnostics of plasma properties and microstructural analysis of hypersonic body material were utilized in the experiments. The investigations were made in the air with normal initial conditions. Through the experiment, the body, formed in the process of compression by products of detonation of cumulative shell-hole (CSH), moved between central transmitting and receiving high-frequency QDE's antennas [11, 24] (offset zone plates Reley-Wood with the relative hole $\approx 1$, diameter $40 \lambda$, were $\lambda=0.004 \mathrm{~m}$ of wavelength). A photograph of the equipment is shown in Fig. 8. The radar chamber consists of a 3.5 meter-long tank, 1.5 meter in diameter, located at the middle of the ballistic range. The uprange end of the tank is lined with microwave absorbing material to minimize the effect of range wall reflections on the radar. The radar reflector, which is made of thin sheet aluminum, is suspended across the flight line at $45^{\circ}$ to the flight axis. The supporting framework is designed to enable the sheet to be mounted easily and accurately in position. The sheet is replaced after each firing. The time of body flight to the high-frequency section was several times longer than the time of relaxation of the local temperature of the body, taken from the equation of heat conduction:

$$
\mathrm{t} \approx \rho \mathrm{c}_{\mathrm{p}} \mathrm{L}^{2} \chi^{-1}
$$


where $\rho$ - density, $c_{\mathrm{p}}$ - specific heat, $\chi$ - the coefficient of specific heat of body material, $\mathrm{L}$ - the scale of irregular warning up of the material in the given condition, probably having the size similar to the size of the grain on the surface of the flying body.

For the full-scale experimental investigations the explosive chambers developed under the leadership of professor V.F.Minin as described at [25] were used (see figure 2).

We have used orientation imaging microscopy (OIM) to study the evolution of the grain boundary character distribution in copper as a function of annealing time. The copper shaped-charge liner material was mechanically processed to obtain the usual conical shape. A metallographic sample was cut from the wall of the cone and polished on a throughthickness plane parallel to the axis of the cone. The grain boundary character distribution was characterized using OIM. The average size of the grain of microstructure of CSH was observed also by it`s length in three cross-sections on the microedges. The size of the grain was regulated by finding regimes of warmer $\mathrm{CSH}$ material. A metallographic sample was polished on a through-thickness plane parallel to the axis of symmetry. The grain boundary character distribution was characterized using orientation imaging microscopy. The observed trend was that the factor of "random" grain boundaries generally decreased with annealing while the grain size increased by less then a factor of 2.5 .

At the first stage exploratory laboratory experiments were carried out using own plasma jets expelled from 17-gram conical shaped charges (without the metal liner). Measured conductivities were in the range of $4.5 \mathrm{kS} / \mathrm{m}$ for unseeded Octol charges and $23 \mathrm{kS} / \mathrm{m}$ for seeded Octol charges containing $2.2 \%$ potassium carbonate by mass.

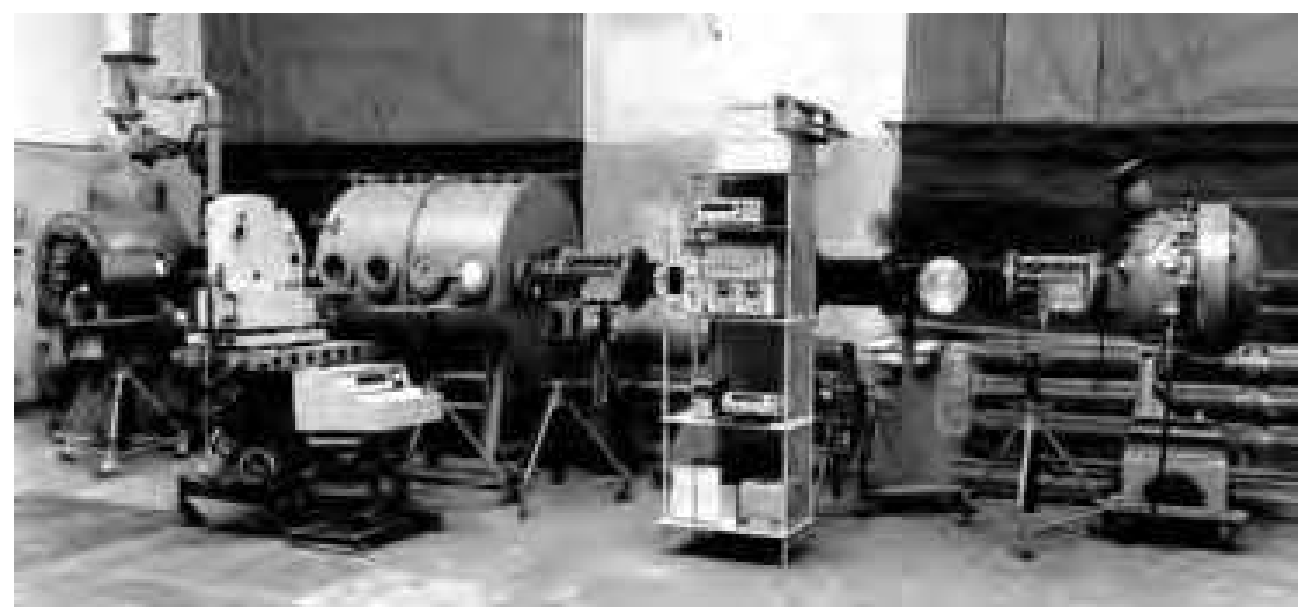

Fig. 8. The experimental plant. 


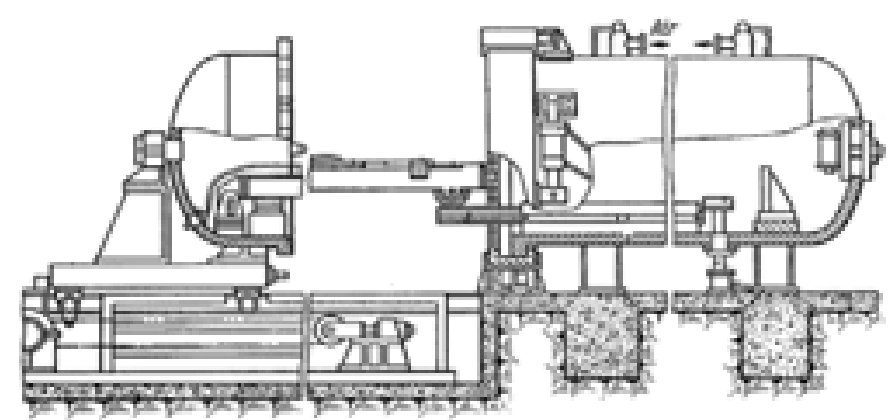

Fig. 9. The explosive chamber [25].

In Fig. 10, typical signals from the $\mathrm{Cu}$ and $\mathrm{Al}$ body are shown. Fig. 10 shows the dependence of the time of existence of the plasma material with CDP on the size of microstructure grain of CSH material, which was obtained through processing of experimental data for the $\mathrm{Cu}$ body. While making the given dependence the data of three series of experiments were used, in which there were 10-15 experiments. The sizes of the CSH material were $\delta=7-10,15$ $25,80-100$ micron. Taking account that the size of the grain on the inner surface of CSH is equal to the size of the surface on the body, fig. 11. From this data, we can see that the size of grain structure on the surface of a high-velocity body greatly influences the electrophysical properties of plasma with CDP. Introducing the particles of metal into the CDP in the plasma track influence it's electromagnetic properties through thermoelectronic emission from their surface. Thus the increasing of the grain size of metal microstructure on the body surface probably leads to the increasing of the charged particles in plasma. And the surface of a shaped charge jet is in a solid state. It could be mentioned that in a classic experiment von Holle and Trimble, see [14], measured the surface temperature of a copper liner near the tip and concluded the jet surface temperature was around $500 \mathrm{C}$. They developed their temperature measurement technique for shocked materials based on two-color infrared radiometry. However, the use of only two colors (wavelengths) indicates that the measured results are not as accurate as they would be if more colors were obtained.
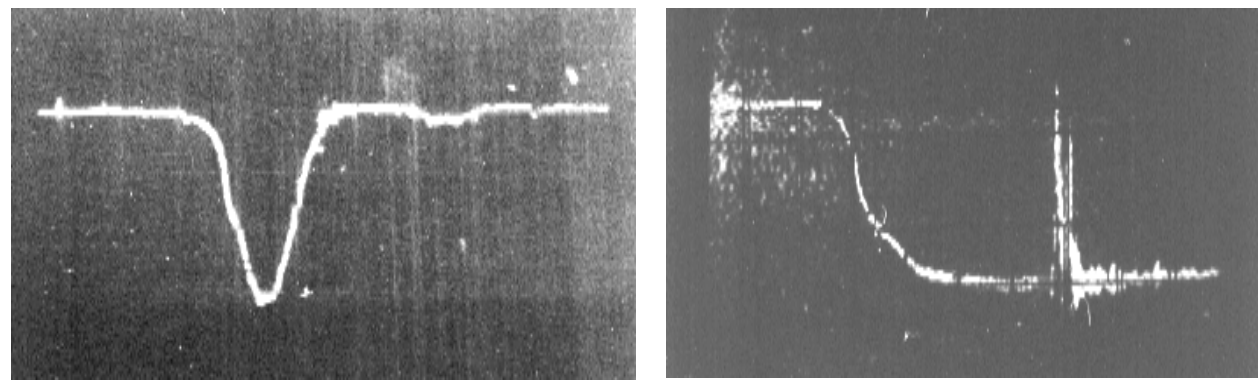

Fig. 10. The typical signals from Cu-body (left) and Al-body (right).

Thus, the above mentioned results of the experiments show that while obtaining of plasma with CDP, appearing in the air though movement of high-velocity bodies and studying their 
electrophysical properties, it is necessary to take into account the influence of the microstructure of the surface of the body. This phenomenon may be used, for example, to create remote quasistationary, impulse or moving reflection of microwaves. This impulse antenna is shown in Fig. 12-14. The length of a plasma body is about several tens meters.

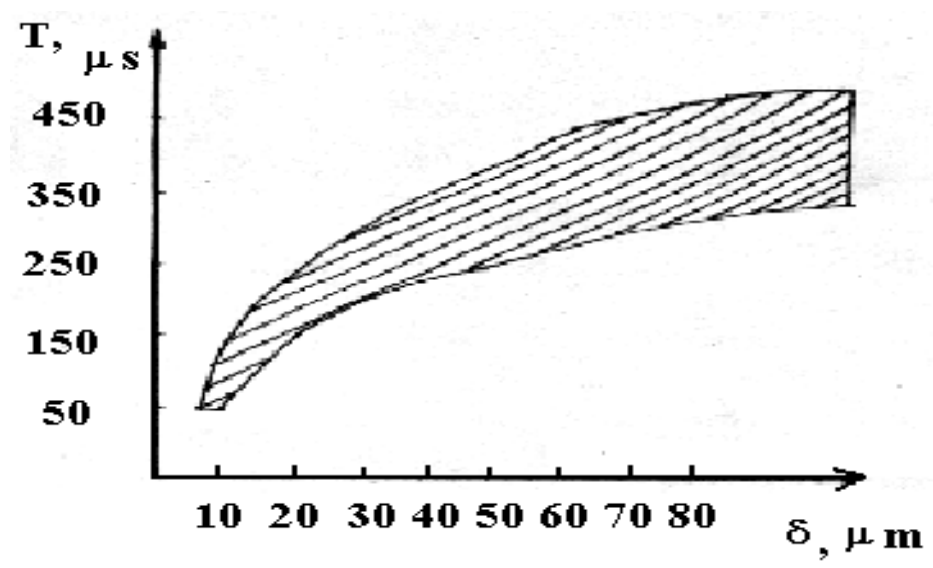

Fig. 11. The dependence of the time of existance of plasma with the CDP on the size of microstructure grain of $\mathrm{CSH}$ material for $\mathrm{Cu}$ body.

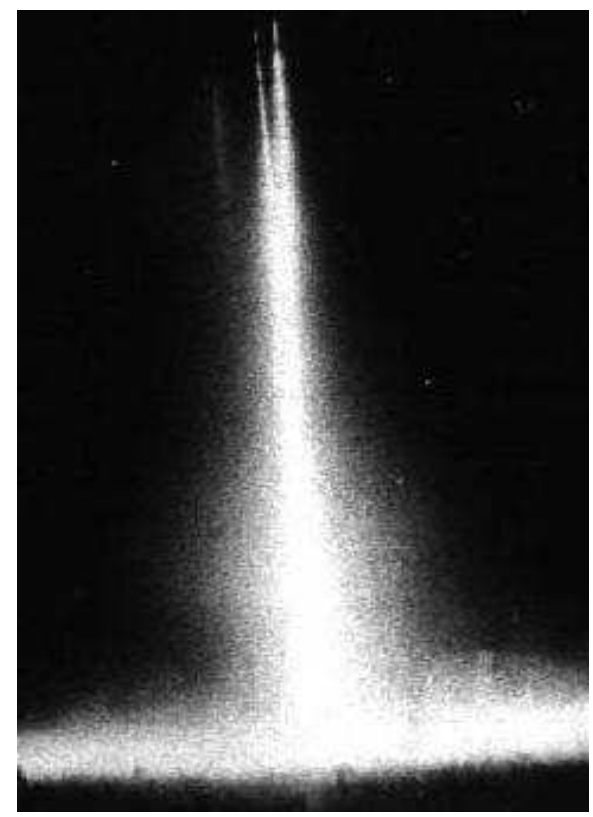

Fig. 12. The plasma impulse antennas created in the air by a hypervelocity Al body. 

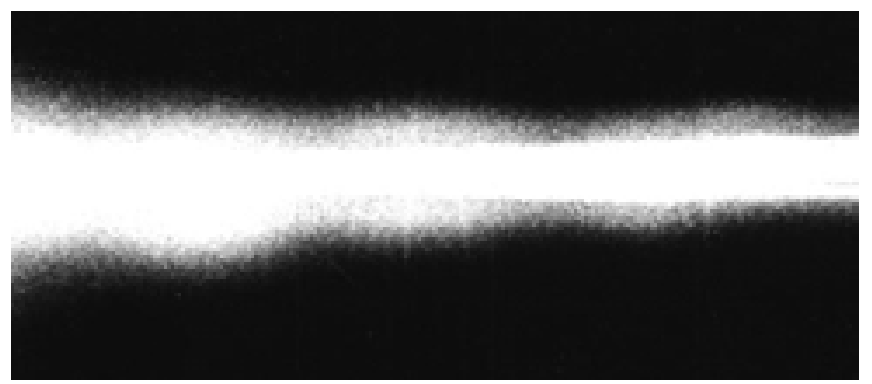

Fig. 13. Fragment of the plasma antenna shown the impulse character of the surface particle erosion.

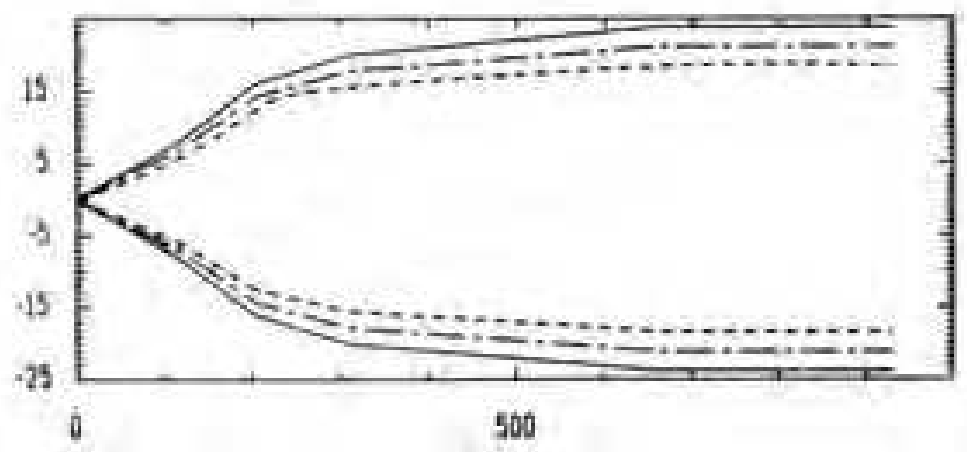

Fig. 14. The typical example of the plasma body renovated from the data of the transmitted coefficient of the mm-waves. The initial stage is shown.

For the Al body with speed about $6 \mathrm{~km} / \mathrm{sec}$ it was shown [10] that the length of a plasma antenna can reach several tens meters. The principal scheme of such type of antenna is shown in the figure 15.

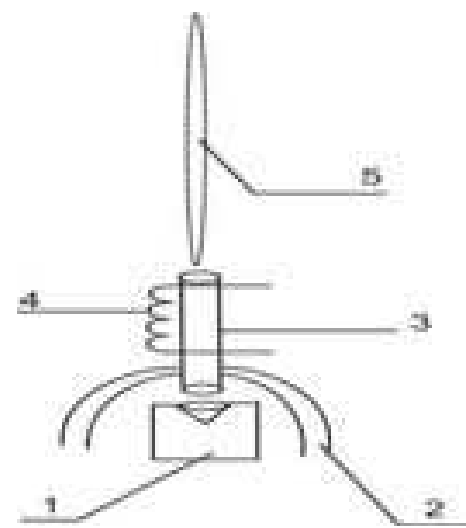

Fig.15. Principal scheme of shaped charge antenna: 1 - shaped charge, 2 - explosive chamber, 3 - tube, 4 - coil, 5 - plasma. 


\section{Future investigations}

It could be noted [26] detailed discussions of the shaped charge concept and an extensive list of sources (too numerous to list here) are available elsewhere. This concept is not well understood by people outside the warhead community. For example, the jet is not "cutting plasma", it is not a liquefied or molten metal jet, the jet temperature is not 20,000 C, and the density of the jet is not several times that of steel, etc. [26].

The main physical problems today in applications to plasma antenna design are as follows. Why do alloys not perform as well as pure metals (with a few exceptions)? Along these same lines, it is known that fine grain liner materials perform better than coarse grain materials. What is the optimum grain size (for materials other than copper, where fine grain liners perform better than coarse grain liners [27])? What is the preferred grain orientation/texture? What about metal purity? (Note that determining the optimal microstructure and mechanical properties for the liner would determine the preferred fabrication method). Should the grain size of the explosive components be fine or coarse to match the grain size present in the liner? Another area of interest is jet particulation or breakup. Can one predict the necking and fracture process of a hypervelocity jet stretching due to its velocity gradient?

Other areas of interest are scaling. Typically, shaped charges can be scaled (homologous scaling) over a charge diameter range of about 1.5 inches to 7 inches. For small charges, the precision/tolerance requirements are hard to achieve and the detonation physics involved does not scale. For large charges, the liner metallurgy is harder to control and the explosive loading is more difficult (may have to be done in stages). Are other, not homologous, scaling laws possible?

Finally, the jet temperature is in general unknown and its prediction by hydrocodes (large computer codes) is difficult and driven by the constitutive equation and equation of state used in the calculation. What is the gradient of temperature, tip to tail, for a shaped charge jet? Recovered jet particles and slugs indicate regions of at least localized melting. What is the interior temperature of the jet? [14]

As it was mentioned below the length of metal shaped charge jet is limited by the value of $\mathrm{L}$ $<10 \mathrm{D}$, where D is a liner diameter. Today as it was shown in [28] the largest shaped charges are available. For example, in [28] a parametric study was conducted using the Shaped Charge Analysis Program code to design 28 inch $(711 \mathrm{~mm})$ outside diameter of shaped charge. The total charge weight was about 900 pounds. The total weight of Octol explosive was about 600 pounds. So the length of shaped charge metal jet (antenna) about $7-10 \mathrm{~m}$ is available.

The length of plasma dielectric shaped charge antenna is also depends on the dimensions of shaped charge. As it was shown in [10] the length of such type of antenna about several hundreds meters are available (figure 16).

Also new physical principles of shaped charge design in applications to plasma antenna must be developed [29-32]. For example, academic prof. V.F.Minin [34] at the beginning of $1960^{\text {th }}$ discovered a new shaped charge with cylindrical liner $[13,29]$. Such type of shaped charge could be also applied to plasma antenna design (figure 17). 


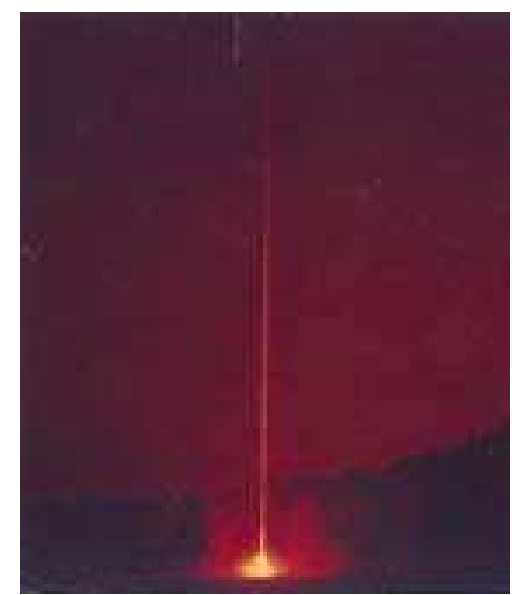

Fig. 16. Dielectric shaped charge antenna.

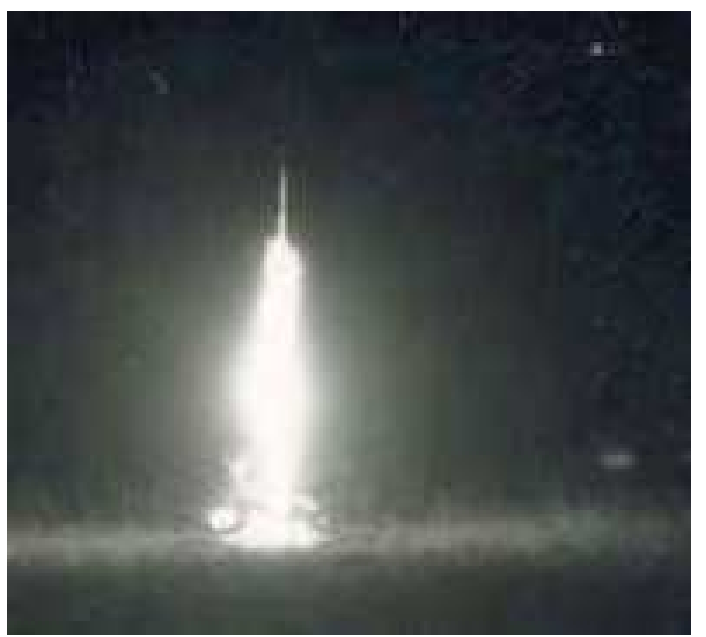

Fig. 17. Plasma dielectric antenna based on shaped charge with cylindrical liner.

As it was mentioned below the jet properties depend on the charge case and liner shape, released energy, and the liner mass and composition. Also the plasma properties depend on the type of material on the surface of the jet and the square of a jet surface. To increase the erosion process from the surface of a jet the unconventional shaped charge can be investigated.

As previously described, conventional shaped charges initiate an explosive material to collapse a liner material about a cavity defined by the liner. The collapsing liner material moves axially inwardly toward the longitudinal axis and simultaneously moves outwardly in the direction of the detonation wave to generate a high velocity jet. Energy from the detonation wave is transferred to the individual particles of the collapsing liner material. For example to increase the jet diameter the forced jet formation principle $[29,31]$ could be apply - 
by resisting collapse of the liner toward the longitudinal axis, and by maintaining a jet diameter greater than conventional jets.

Also it is not a direct subject of a present chapter it could be mentioned that some new perspective shaped charge liners for the plasma antenna development were discovered and investigated under the scientific leadership of academic Prof. Dr. Vladilen F. Minin [34], they are:

- Star-shaped liners: in the cross section from the charge butt end, the liner has a four-ray shape. The distance from the charge axis to the liner decreases with the charge length in an unproportional manner. Therefore, the two-dimensional cross sections of the liner are different in different planes. That is why the liner has four planes of symmetry. Some of the experimental geometric dimensions were as follows: the liner thickness $3.5 \mathrm{~mm}$, the largest radius of the liner 27.5 $\mathrm{mm}$, the shell thickness $5 \mathrm{~mm}$, the external radius of the shell $32.5 \mathrm{~mm}$, the length of the HE charge $70 \mathrm{~mm}$ (see figure 18).

- W-liner: some results of preliminary studies of cumulative charges; with the linings that we name $\mathrm{W}$-shaped linings. Tests with the $\mathrm{W}$-shaped charges have shown that massive jets (without the formation of a slug) with velocities of $1.5-5 \mathrm{~km} / \mathrm{s}$ can be formed at large focusing distances (see figure 19). It could be noted that the $\mathrm{W}$-shaped lining can be bimetallic, i.e., its central and peripheral parts are made of different metals. So the metal in inner surface of a jet can be made from the metal with the specific properties to plasma formation $[13,29,30]$.

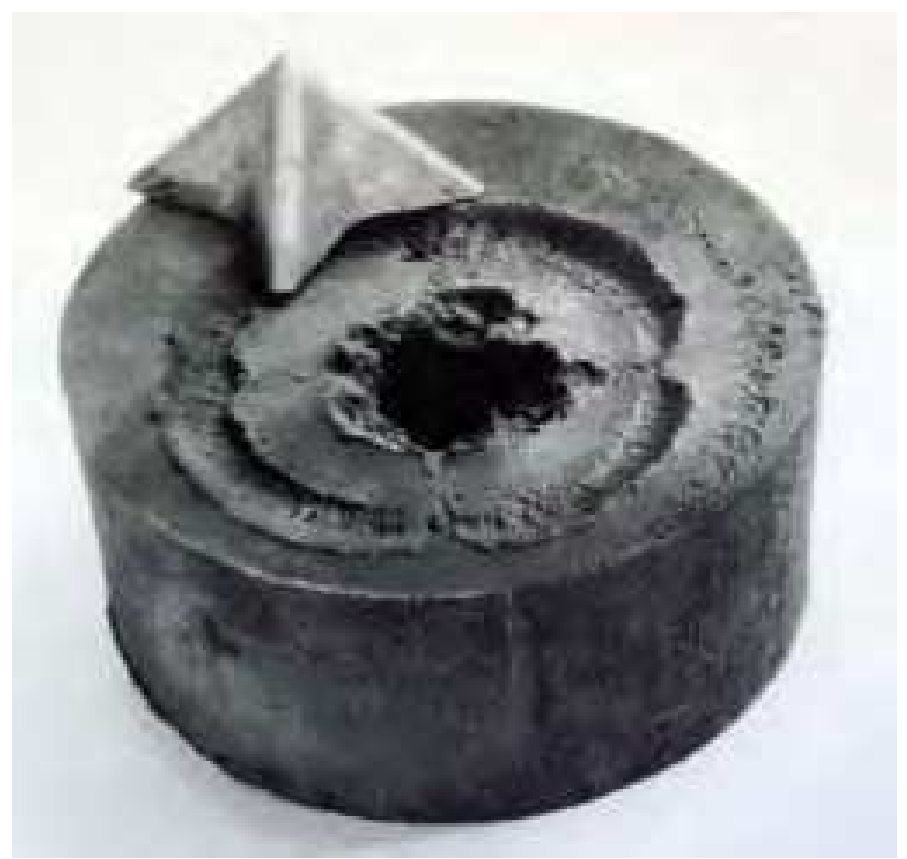

Fig. 18. Star-like liner for the shaped charge and the target. 


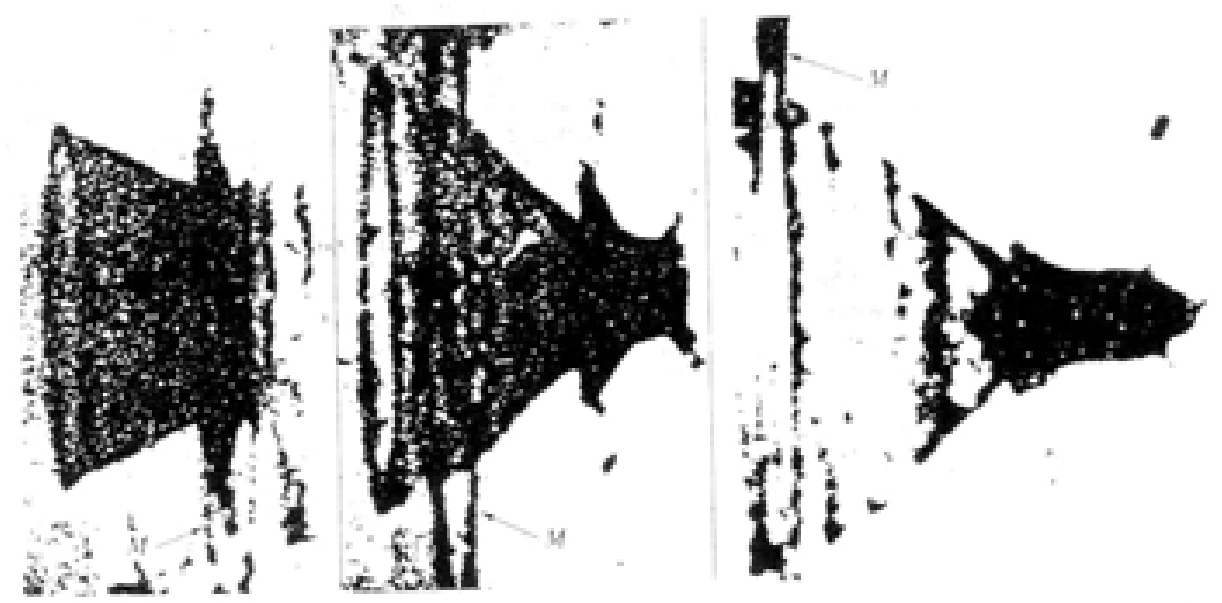

Fig. 19. X-ray of initial stage of a jet formation from W-type liner.
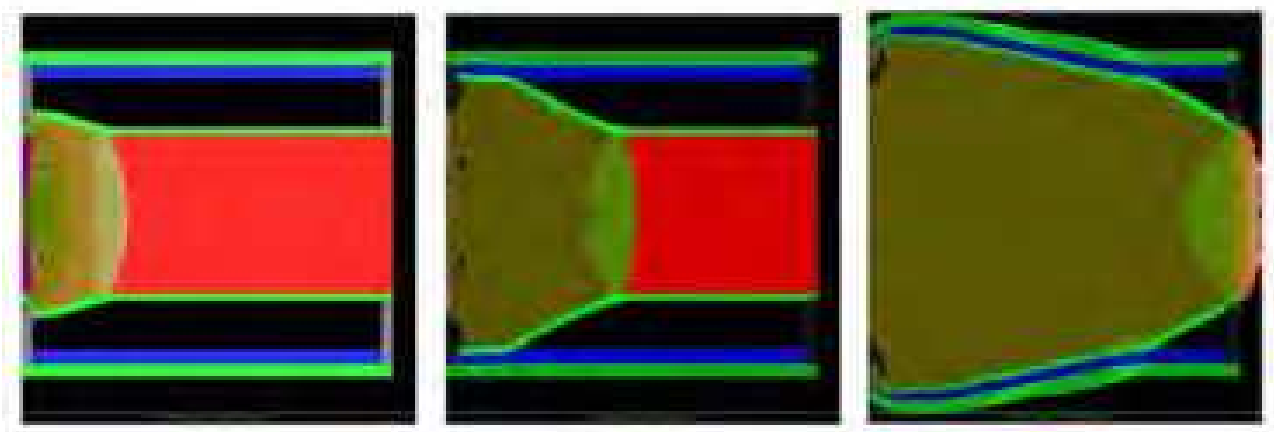

Fig. 20. Simulation of the FCG operation developed under the scientific leadership of Prof. V.F.Minin.

Other aspect of the future explosive plasma antenna development is as follows. Pulse power levels obtained now have the units of GW values. That power is determined by high values of the antenna input voltage (units of megavolts). It can leads to breakdowns in the feeder and antenna. Such a problem also arise in the making of mobile sources that have power of tens megawatt value. When such sources are made on the magnetic cumulative generator (MCG) or flux compression generator (FCG) bases the task of decreasing of dimensions and weight of them keeps being relevant. FCGs use the chemical energy from high explosives to accelerate a metallic conductor that traps and compresses a magnetic field initially created by a seed energy source such as a capacitor bank, battery, or another pulsed generator (figure 20) [35, 36].

The output voltage in such generators as a rule exceeds $30 \mathrm{KV}$ value under there volume in 0.51 and mass in $300 \mathrm{~g}$ values. 


\section{Acknowledgement}

The author would like to thanks Vedran Kordic for invitation me as an editor of the present book. The preparation of this chapter would not have been possible without the support of our father and mother.

\section{References}

1. Anishchenko, Y. V. (1997). Radiation Initiated by a Surface Wave Propagating along a Long Plasma Column with a Varying Impedance. Plasma Physics Reports, Vol. 23 No. 12 , pp. $1001-1006$.

2. Askar'yan G. A. (1982). Letters to journal of technical physics (JTF), Vol. 8, pp. 1131.

3. Dwyer, T.J., Greig, J.R., Murphy, D.P., Perin, J.M., Pechacek, R.E., and Raleigh, M. (1984). On the Feasibility of Using an Atmospheric Discharge Plasma as an RF Antenna. IEEE Transactions on Antennas and Propagation, Vol. AP-32. No.2, pp.78-83.

4. Alexeff, I., Kang, W. L., Rader, M., Douglass, C, Kintner, D., Ogot, R., and Norris, E. (2000). A Plasma Stealth Antenna for the U. S. Navy-Recent Results. Plasma Sources and Applications of Plasmas II, November 18.

5. Larry L. Altgilbers et al. (1998). Plasma antennas: theoretical and experimental conciderations. Plasmadynamics and Lasers Conference, 29th, Albuquerque, NM, June 15-18. AIAA-1998-2567.

6. Zhang T. X., Wu S. T., Altgilbers L. L., Tracy P., and Brown M. Radiation Mechanisms of Pulsed Plasma Dielectric Antennas, 2002, AIAA-2002-2104.

7. Novikov V.E., Puzanov A.O., Sin'kov V.V., Soshenko V.A. (2003). Plasma antenna for magneto cumulative generator. Int. Conf. On antenna theory and techniques, Sept. 912. Ukraine, pp. 692-695.

8. Shkilyov A.L., Khristenko V.M., Somov V.A., Tkach. Yu.V. (2003). Experimental Investigation of Explosive Plasma Antennas. Electromagnetic phenomenon's, Vol. 3, N 4(12), pp.521-528.

9. Schoeneberg N.J. (2003). Generation of transient antennas using cylindrical shaped charges, A THESIS IN ELECTRICAL ENGINEERING, Submitted to die Graduate Faculty of Texas Tech University in Partial Fulfillment of the Requirements for the Degree of MASTER OF SCIENCE IN ELECTRICAL ENGINEERING.

10. Minin I., Minin O. (2002). The possibility of impulse plasma antenna creation, Proceeding of the 6th Russian-Korean Int. Symp. On Science and Technology, June 24-30, Novosibirsk, Russia. v.2, pp. 289 - 292.

11. Minin I.V., Minin O.V. (1998). Diffractional quasioptics. 180 p. Moskow: ImformTei.

12. Kennedy, D. R. (1983). History of the Shaped Charge Effect, the First 100 Years, 75p. U. S. Department of Commerce, AD-A220 095.

13. Minin I.V. and Minin O.V. (2003). World's history of shaped charge. Proceeding of the Russian conference "Science, Industry and defense", Novosibirsk, April 23-25, pp. 51-53.

14. Walters, W.P. and Zukas J.A. (1989). Fundamentals of Shaped Charges. 130 p. CMCPress. Baltimore, MD.

15. Wolsh J., Shreffler, Willing F. (1954). The limiting conditions for jet formation at high speed. Moskoy.: Mechanics, 1(23), (in Russian). 
16. Godunov S., Deribas A., Mali V. (1975). About the influences of viscous of metall to the jet formation process. Fisika gorenia i vzriva (in Russian), Vol. 11, № 1.

17. Pei Chi Chon, J.Carleone, R.Karpp. (1976). Criteria for jet formation from impinging shell and plates. J. Appl. Phys., Vol. 47.

18. Birkhoff G., McDougall D., Pugh E., Taylor G. (1948). Explosives with lined cavities. J. Of Appl. Phys. Vol. 19, pp. 563-582.

19. Lavrent'ev M. (1957). The shaped charge and principles of it operations. Uspehi matem. Nauk (in Russian). Vol. 12, № 4, pp.41-56.

20. Minin I.V., Minin O.V. (2003). New criterion of cumulative jet formation. 7th Korea-Russia International Symposium on Science and Technology "KORUS 2003",June 29-July 2, 2003. University of Ulsan, Ulsan, Korea, vol.3, Pages: 93 - 94.

21. V.F.Minin, I.V.Minin, O.V.Minin. Criterium of jet formation for the axisymmetrical shaped charge//Izvestia Vuzov, Povoljskii region, 2006, № 6 (27), pp. 380-389 (in Russian).

22. Neuber, A.; Schoeneberg, N.; Dickens, J.; Kristiansen, M. (2002). Feasibility study of an explosively formed transient antenna. Power Modulator Symposium, 2002 and 2002 High-Voltage Workshop. Conference Record of the Twenty-Fifth International Volume, Issue, 30 June-3 July 2002, pp. $374-377$.

23. Minin O.V. and Minin I.V. (2000). The influence of the grain size of microstructure of the surface layer material of a hypersonic body on the properties of air plasma.- The $10^{\text {th }}$ Electromagnetic Launch Technology Symposium, Institute for Advanced Technology, San Francisco, California, USA, April 25-28, 2000. The book of abstracts, pp. 160. See also: Minin O.V. and Minin I.V. (2000). The influence of the grain size of microstructure of the surface layer material of a hypersonic body on the properties of air plasma. // Computer optics, N20, pp.93-96. http://www.computeroptics.smr.ru/KO/PDF/KO20/ko20221.pdf

24. Minin I.V., Minin O.V. (2003). Diffraction optics of millimeter waves. - IOP Publisher, Boston-London.

25. Patent of the USA № 4100783. Minin V.F. et al. Installation for explosion machining of articles., Jul.18, 1978.

26. Walters. W.P. An Overview of the Shaped Charge Concept http://www.scribd.com/doc/6193899/An-Overview-of-the-Shaped-ChargeConcept

27. Dante, J. G. and Golaski, S. K. (1985). Micrograin and Amorphous Shaped Charge Liners. Proceedings of ADPA Bomb and Warhead Section, White Oak, MD, May 1985.

28. Manuel G. Vigil. (2003). Design of Largest Shaped Charge: Generation of Very Large Diameter, Deep Holes in Rock and Concrete Structures. SANDIA REPORT SAND2003-1160, Unlimited Release, Printed April 2003.

29. Minin I.V., Minin O.V. (2002). Physical aspects of shaped charge and fragmentational warheads. 84 p. Novosibirsk, NSTU.

30. Minin I.V., Minin O.V. (1999). Some new principles of cumulative jet formation. Collection of works NVI (in Russian), Vol. 7, pp. 19-26. Patent SU № 1508938 (1987). Minin V.F., Minin I.V., Minin O.V. and et. Devise for plasma jet forming.

31. Minin I.V., Minin O.V. (1992). Analytical and computation experiments on forced plasma jet formation. Proc. of the $2^{\text {nd }}$ Int. Symp. on Intense Dynamic Loading and Its Effects. Chengdu, China, June 9-12, 1992, pp. 588-591. 
32. Minin I.V., Minin O.V. (2005). Cumulative plasna jet formation for acceleration of macroparticles, 9th Korea-Russia International Symposium on Science and Technology / KORUS 2005, June 26-July 2, 2005, NSTU, Russia.

33. Minin I.V., Minin O.V. (2006). Experimental research on reactive type plasma antenna for secure WiFi networks, 8th Int. Conf. On actual problems on electronics instrument engineering, Proceeding, APIEE-2006, v.2, Novosibirks, Sep.26-28, 2006.

34. Prof. Dr. V.F.Minin http://www.famous-scientists.ru/2677/

35. Minin F.V., Minin I.V., Minin O.V. (1992) Technology of calculation experiments // Mathematical modeling, v.4, N 12, pp. 78-86 (in Russian).

36. Minin F.V., Minin I.V., Minin O.V. (1992) The calculation experiment technology, Proceedings of the $2^{\text {nd }}$ Int. Symp. on Intense Dynamics loading and its effects, Chengdu, China, July 9-12, pp.581-587. 


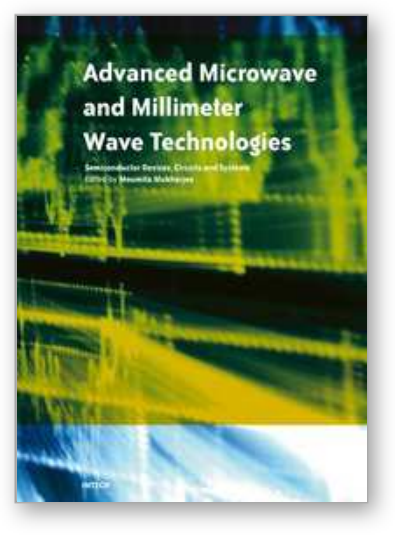

\section{Advanced Microwave and Millimeter Wave Technologies Semiconductor Devices Circuits and Systems}

Edited by Moumita Mukherjee

ISBN 978-953-307-031-5

Hard cover, 642 pages

Publisher InTech

Published online 01, March, 2010

Published in print edition March, 2010

This book is planned to publish with an objective to provide a state-of-the-art reference book in the areas of advanced microwave, MM-Wave and $\mathrm{THz}$ devices, antennas and systemtechnologies for microwave communication engineers, Scientists and post-graduate students of electrical and electronics engineering, applied physicists. This reference book is a collection of 30 Chapters characterized in 3 parts: Advanced Microwave and MM-wave devices, integrated microwave and MM-wave circuits and Antennas and advanced microwave computer techniques, focusing on simulation, theories and applications. This book provides a comprehensive overview of the components and devices used in microwave and MM-Wave circuits, including microwave transmission lines, resonators, filters, ferrite devices, solid state devices, transistor oscillators and amplifiers, directional couplers, microstripeline components, microwave detectors, mixers, converters and harmonic generators, and microwave solid-state switches, phase shifters and attenuators. Several applications area also discusses here, like consumer, industrial, biomedical, and chemical applications of microwave technology. It also covers microwave instrumentation and measurement, thermodynamics, and applications in navigation and radio communication.

\section{How to reference}

In order to correctly reference this scholarly work, feel free to copy and paste the following:

Igor V. Minin and Oleg V. Minin (2010). Explosive Pulsed Plasma Antennas for Information Protection, Advanced Microwave and Millimeter Wave Technologies Semiconductor Devices Circuits and Systems, Moumita Mukherjee (Ed.), ISBN: 978-953-307-031-5, InTech, Available from:

http://www.intechopen.com/books/advanced-microwave-and-millimeter-wave-technologies-semiconductordevices-circuits-and-systems/explosive-pulsed-plasma-antennas-for-information-protection

\section{INTECH}

open science | open minds

\author{
InTech Europe \\ University Campus STeP Ri \\ Slavka Krautzeka 83/A \\ 51000 Rijeka, Croatia \\ Phone: +385 (51) 770447 \\ Fax: +385 (51) 686166 \\ www.intechopen.com
}

\author{
InTech China \\ Unit 405, Office Block, Hotel Equatorial Shanghai \\ No.65, Yan An Road (West), Shanghai, 200040, China \\ 中国上海市延安西路65号上海国际贵都大饭店办公楼 405 单元 \\ Phone: +86-21-62489820 \\ Fax: +86-21-62489821
}


(C) 2010 The Author(s). Licensee IntechOpen. This chapter is distributed under the terms of the Creative Commons Attribution-NonCommercialShareAlike-3.0 License, which permits use, distribution and reproduction for non-commercial purposes, provided the original is properly cited and derivative works building on this content are distributed under the same license. 